\title{
A High Voltage MWT Module with Improved Shadow Performance
}

\author{
Anna J. Carr, Mark J. Jansen, Maarten de Bruijne, Lars Okel, Mario Kloos, Wilma Eerenstein \\ ECN Solar Energy, P.O. Box 1, 1755 ZG Petten, The Netherlands, corresponding author: carr@ecn.nl
}

\begin{abstract}
In this paper we present a module concept designed for better performance under shadow conditions, incorporating also lower BOS costs. This concept is a highvoltage, low-current, shadow resistant, back-contact module concept. The experimental results under partial shading conditions for mini-modules having a Voc of $39.8 \mathrm{~V}$ show a substantial improvement in shadow performance. The concept is based on the existing ECN MWT (Metal Wrap Through) backcontact technology [1], where the standard MWT cells are replaced by series connected "mini" cells. With the flexibility of the back-foil system we are able to approach a more linear shadow response for our module.
\end{abstract}

Index Terms - back-contact, bypass diodes, crystalline silicon, high voltage, photovoltaic modules, shadow performance.

\section{INTRODUCTION}

There are several advantages in high-voltage, low-current photovoltaic modules when compared to standard modules that produce between 8-9A and 30-40 V. A lower current, around $0.5 \mathrm{~A}$, allows for the use of smaller and also more bypass diodes which in turn reduces shadow losses. Lower currents can also be used to reduce material consumption as less metal is required to carry the current. Higher voltages enable simpler and more efficient inverter topologies thereby reducing the losses in the $\mathrm{DC}$ to $\mathrm{AC}$ conversion, and making it possible to reduce BOS costs.

Cutting up full size cells to produce a higher voltage is not new and there are several commercially available products targeted at the small off-grid and battery charging applications. These modules are typically in the range of 2$40 \mathrm{Wp}$, producing the $12 \mathrm{~V}$ required for battery charging. They use H-pattern cells and standard tabbing and stringing production. These products have a very specific market and are not intended for large area, high power installations. At the other end of the spectrum there are more exotic examples of high voltage module technologies including Sliver [2] and XIS [3], as well as many thin film technologies.

As the market and application of BIPV (Building Integrated Photovoltaics) and BAPV (Building Applied PV) develops, the question of shadow performance of the PV modules becomes more prominent. Modules installed on rooftops or façades will be far more susceptible to shading from trees, other buildings, chimneys etc. Solutions to this problem include the use of micro-inverters and power optimizers making each module independent from the others in the system.

The high voltage shadow resistant module described here enables high voltages (450+Volts) to be reached in a full sized
(6 x 10 cell equivalent) module, ideal for simplification of the inverter topology, in for instance a three phase micro-inverter [4]. Furthermore, it enables a module that has 60 essentially shadow independent areas, in place of the standard module which has 3 large bypass diodes in the junction box protecting 3 strings of 20 cells, further boosting system performance.

\section{The High Voltage Module}

\section{A. Module Concept}

The shade resistant high voltage module described here begins with a standard MWT cell. This standard $15.6 \mathrm{~cm} \mathrm{x}$ $15.6 \mathrm{~cm}$ cell is physically divided, using laser scribing and cleaving, into its 16 unit cells as shown in Fig. 1.
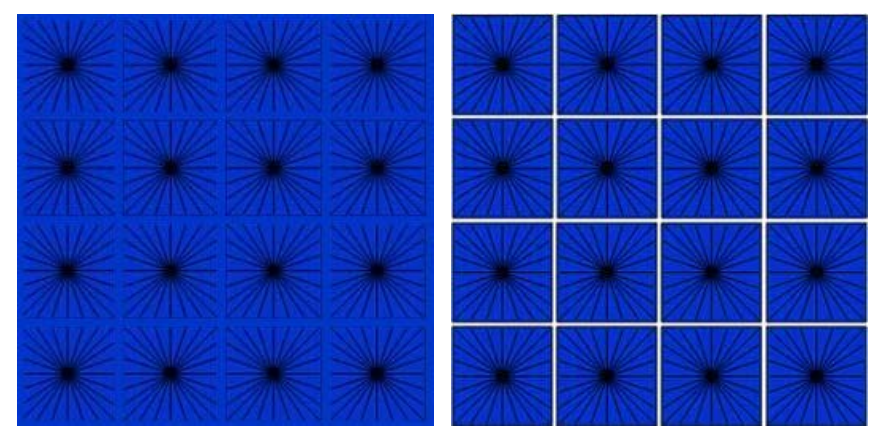

Fig. 1. Schematic showing a standard MWT cell (left) and the separated unit cells of the new concept (right).

These mini-cells can then be assembled into modules using the MWT process. A clever use of the patterning options of the conductive back sheet foil technology allows for a very flexible module interconnection design. The back foil is patterned to allow for the series connection of the mini-cells and for the integration of diodes to protect smaller areas inside the module, in this case each 16 mini-cell group. This leads to a full size module geometry of 60x16=960 mini-cells connected in series and a $450+\mathrm{V}$ module voltage.

\section{B. Mini Cells}

The mini-cells for the prototype modules were processed in our cell line starting with a standard p-type process on full square mono-crystalline wafers. After the application of the SiNx anti-reflection coating 16 vias were laser drilled in each wafer. The cells were printed using a pattern consisting of 
separated and identical unit cells. This mini-cell pattern ensures that no metal is laser fired into the cell at the subsequent laser scribing step, as this could cause shunting in the cells.

Once the cells had been scribed and cleaved they were measured using a modified measuring chuck to accommodate these mini-cells. These modifications lead to some uncertainties in the cell IV measurements, particularly in the Jsc and FF.

Laser scribing and cleaving the cells into mini-cells can lead to increased edge recombination as this fresh cleaved edge is un-passivated and the edge to cell area ratio is increased. Comparing the mini-cells to standard MWT cells we saw an average loss in $\mathrm{Voc}$ of $4 \mathrm{mV}(0.65 \%)$. The effect of the number of cleaved edges, 2,3 or 4 on the cell measurements was investigated within the 502 mini-cells measured. It was found that that there was no measurable difference in Voc across the groups, and there was a small but distinct decrease in Isc with an increase in the number of cleaved edges; see Fig. 2 and Fig. 3. The greater effect on the short circuit current is to be expected and is in line with results reported elsewhere [3].

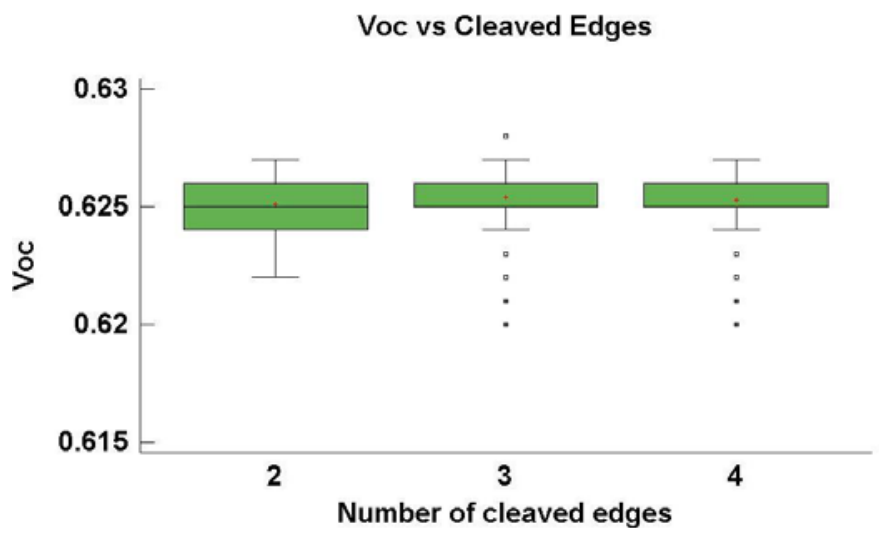

Fig. 2. Voc vs number of cleaved edges

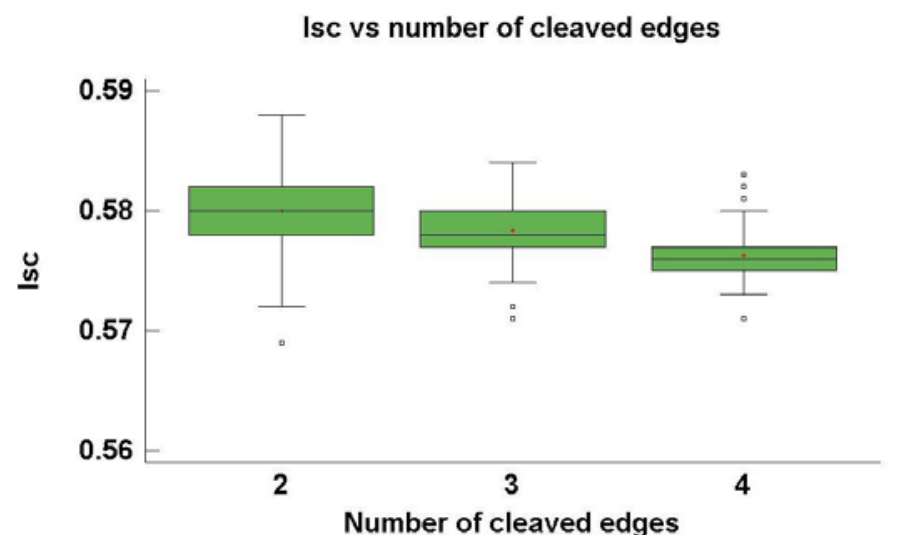

Fig. 3. Isc vs number of cleaved edges

\section{B. Mini Modules}

A series of mini-modules ( 8 x 8 cells) was produced, see Fig. 4. IV measurements were made in our Pasan flash tester. Values of 39.8V Voc, 0.56A Isc, $75.5 \mathrm{FF}$ and efficiencies of $17.2 \%$ were measured on the high voltage mini modules.

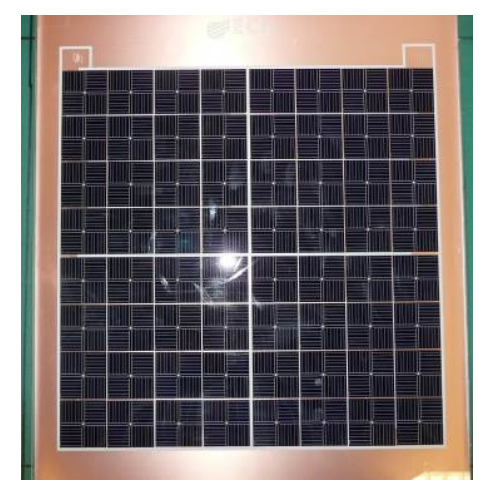

Fig. 4. High-voltage shade resistant mini-module.

The high voltage modules were made both with and without bypass diodes. The bypass diodes were integrated in the module assembly with one bypass diode being installed over each group of 16 mini-cells, representing one standard $15.6 \mathrm{~cm}$ $\mathrm{x} 15.6 \mathrm{~cm}$ cell in a standard module.

\section{Bypass Activation}

The operation of the bypass diodes was confirmed by comparing the output of the modules with and without bypass diodes while completely blocking one mini-cell. The results showed that a module with bypass diodes still produced $73 \%$ of its original power, whereas the module with no bypass diodes only produced $23 \%$, see Fig. 5. Further measurements confirmed the independent functioning of the 4 cell groups when shaded, see Fig. 6.

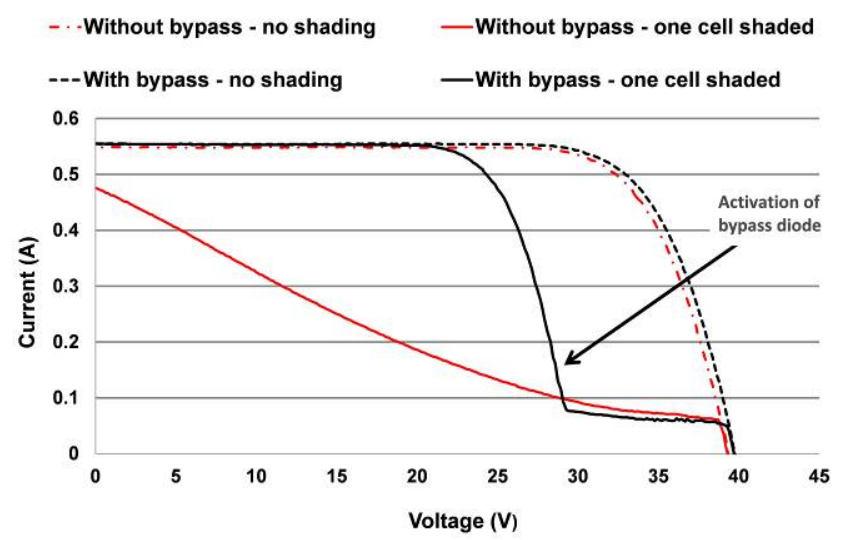


Fig. 5. Proof of principle - The IV results of shading one mini-cell in high-voltage mini modules: with and without bypass diodes. The plot shows the activation of one bypass diode while blocking one mini-cell.

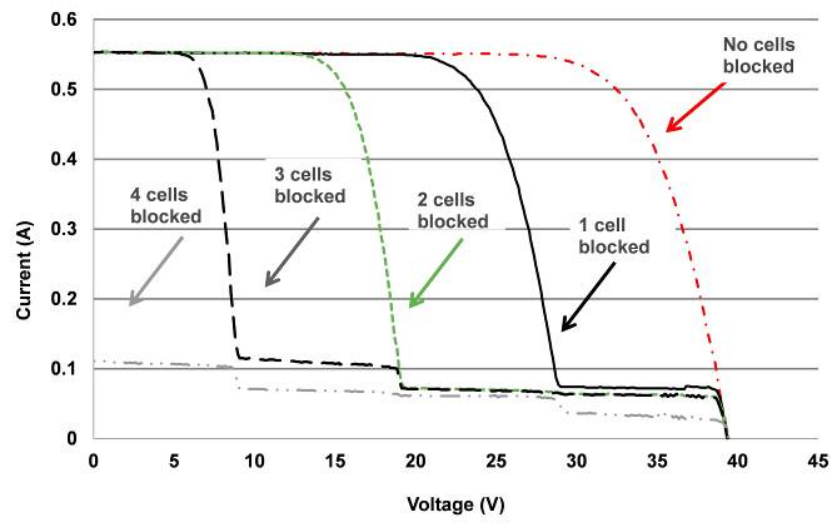

Fig. 6. The effect of blocking one single mini-cell in each of the 4 groups of the mini module. The measured IV curves show the activation of each of the bypass diodes in turn.

\section{SIMULATED SHADOW RESPONSE}

One of the benefits of this module is its resistance to shading. The effects of 5 basic shade scenarios were simulated using the electrical array behavior tool in PVsyst [5]. A full size high voltage module was added to the PVsyst database and the tool was used to compare this with the behavior of a standard 60 cell, 3 string module. The basic shadow scenarios were: a horizontal, 2 vertical, a diagonal and a 'leaf' shade where only one standard cell is shaded. See Fig. 7. Comparing the power output as a percentage of the un-shaded maximum power for these shaded conditions, the high voltage module resulted in a benefit in power output. It was $0 \%$ when a vertical shadow blocks a complete 20 cells string (Fig. 7 B (i \& ii)), and $70 \%$ in the case of the horizontal shade, blocking 20 cells across 3 strings (conventional module) or 20 groups of 16 mini-cells (High voltage) (Fig. 7 A (i \& ii)). See TABLE I for an overview.

TABLE I

SUMMARY OF SHADING SIMULATIONS

\begin{tabular}{|c|c|c|c|}
\hline \multirow{2}{*}{$\begin{array}{l}\text { Shadow } \\
\text { Type }\end{array}$} & \multicolumn{2}{|c|}{$\begin{array}{l}\text { Output relative to } \\
\text { un-shaded } \mathrm{P}_{\max }\end{array}$} & $\begin{array}{l}\text { Power gain } \\
\text { of High } \\
\text { Voltage } \\
\text { Module }\end{array}$ \\
\cline { 2 - 3 } & $\begin{array}{l}\text { Standard } \\
\text { module }\end{array}$ & $\begin{array}{l}\text { High voltage } \\
\text { module }\end{array}$ & $70 \%$ \\
\hline Horizontal & $8 \%$ & $78 \%$ & $0 \%$ \\
\hline $\begin{array}{c}\text { Vertical } \\
(2 \text { columns) }\end{array}$ & $64 \%$ & $64 \%$ & $0 \%$ \\
\hline
\end{tabular}

\begin{tabular}{|c|c|c|c|}
\hline $\begin{array}{c}\text { Vertical } \\
(1 \text { column })\end{array}$ & $64 \%$ & $82 \%$ & $18 \%$ \\
\hline Diagonal & $64 \%$ & $88 \%$ & $24 \%$ \\
\hline 'Leaf' & $64 \%$ & $98 \%$ & $34 \%$ \\
\hline
\end{tabular}

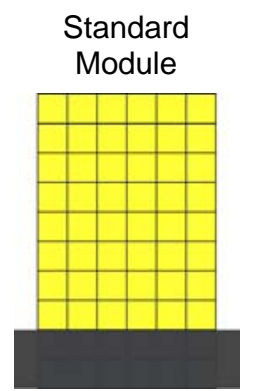

$\mathrm{A}(\mathrm{i})$

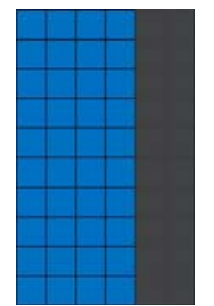

$B(i)$

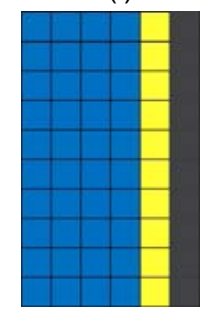

C(i)

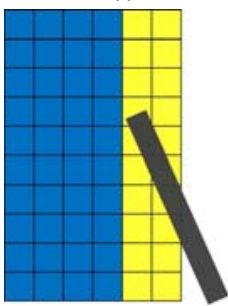

$\mathrm{D}(\mathrm{i})$

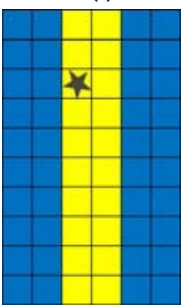

$E(i)$

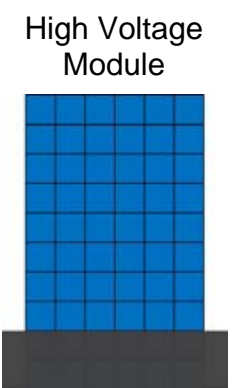

Gain

Legend

A(ii)

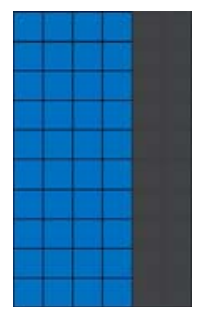

$B($ ii)

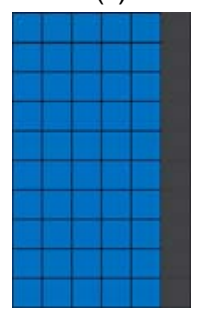

C(ii)

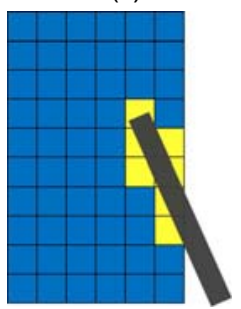

$D(i i)$

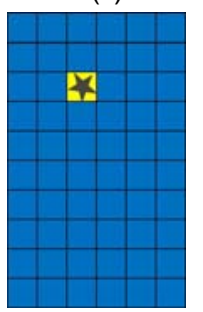

E(ii)

$0 \%$

$18 \%$

$24 \%$

$34 \%$
Fig. 7. Basic shade types examined for standard and high-voltage modules: a) Horizontal, b) Vertical (2 columns), c) Vertical (1 
column), d) Diagonal and e) A 'leaf' shade. The blue areas are the active cells. The yellow areas show the inactive area caused by the shadow (grey) and the string arrangement of the module.

Fig. 8. shows the power voltage curves of the diagonal shade (Fig. 7D): 7 standard cells in one string, or 7 groups of mini-cells are in shadow. The curves show that the power output in the case of the standard module is $64 \%$, while the high voltage module would still produce $88 \%$ of the unshaded rated power, representing a gain of $24 \%$ in the case of the high voltage module.

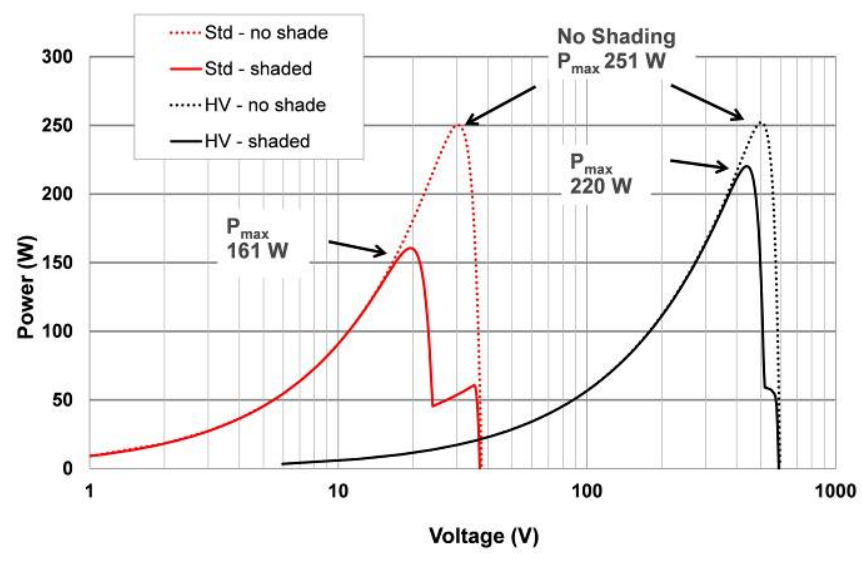

Fig. 8. Power voltage curve showing the results of the simulated diagonal shadow example on full size standard and full size high voltage modules (log scale to compare both high and standard voltages).

\section{CONCLUSION AND OUTLOOK}

We have designed and manufactured back-contact high voltage module prototypes. The modules take advantage of the MWT back foil technology to series connect mini-cells, and integrate bypass diodes.

We have demonstrated the operation and effectiveness of the concept to reduce shadow losses. Furthermore the five basic shadow scenarios to estimate the potential benefit of the technology in full size modules have shown that power gains up to $70 \%$ can be expected (median $24 \%$ ).

The concept has the potential to substantially increase annual yield, particularly useful in BIPV and BAPV applications.

Further developments will include: production and testing of full size 450+ Volt modules, dedicated inverter design, controlled realistic shading tests, outdoor testing and annual yield modeling.

\section{REFERENCES}

[1] M. W. P. E. Lamers, C. Tjengdrawira, M, Koppes, I. J. Bennett, E. E. Bende, T. P. Visser, E. J. Kossen, B. Brockholz, A. A. Mewe, I. G. Romijn, E. Sauar, L. Carnel, S. Julsrud, T. Naas, P. C. de Jong, A. W. Weeber, "17.9\% Metal-wrap-through mc-Si cells resulting in module efficiency of $17.0 \%$ " Progress in Photovoltaics vol. 20(1), pp.62-73, 2011

[2] E. Franklin, A.W. Blakers, V. Everett and K.J. Weber, "A 20\% efficient Sliver ${ }^{\circledR}$ solar cell," in 22nd European Photovoltaic Solar Energy Conference., Milano, Italy; 2007.

[3] A. A. Mewe, M. K. Stodolny, J. A. M. van Roosmalen, P. C. P. Bronsveld, G. J. M. Janssen, M. A. de Keijzer, and A. W. Weeber, "XIS: A Low-Current, High-Voltage Back-Junction Back-Contact Photovoltaic Device,” In $39^{\text {th }}$ IEEE Photovolataic Specialist Conference, Tampa, Florida, USA, 2013.

[4] N. Henze, B. Sahan, R. Burger, W. Belschner, "A Novel AC Module with High-Voltage Panels in CIS Technology”, 23rd European PV Solar Energy Conference and Exhibition, Valencia, Spain 2008

[5] PVsyst V6.10, PV “Study of Photovoltaic Systems”. PVsyst SA, Satigny, Switzerland. www.pvsyst.com 